\title{
Regulation of the regeneration of intestinal stem cells after irradiation
}

\author{
Liping Liang ${ }^{1,2 \#}$, Lijun Shen ${ }^{1,2 \#}$, Guoxiang Fu ${ }^{3}$, Ye Yao ${ }^{1,2}$, Guichao Li $^{1,2}$, Yun Deng ${ }^{1,2}$, Hui Zhang ${ }^{1,2}$, \\ Menglong Zhou ${ }^{1,2}$, Wang Yang ${ }^{1,2}$, Guoqiang Hua ${ }^{3,4}$, Zhen Zhang ${ }^{1,2}$
}

${ }^{1}$ Department of Radiation Oncology, Fudan University Shanghai Cancer Center, Fudan University, Shanghai, China; ${ }^{2}$ Department of Oncology, Shanghai Medical College, Fudan University, Shanghai, China; ${ }^{3}$ Institute of Radiation Medicine, Shanghai Medical College, Fudan University, Shanghai, China; ${ }^{4}$ Institute of Radiation Medicine and Cancer Institute, Fudan University Shanghai Cancer Center, Fudan University, Shanghai, China

Contributions: (I) Conception and design: L Liang, L Shen, Z Zhang, G Hua; (II) Administrative support: None; (III) Provision of study materials or patients: None; (IV) Collection and assembly of data: L Liang, L Shen, G Fu, Y Yao, Y Deng, G Li, H Zhang, M Zhou, W Yang; (V) Data analysis and interpretation: L Liang, L Shen, Z Zhang, G Hua; (VI) Manuscript writing: All authors; (VII) Final approval of manuscript: All authors.

"These authors contributed equally to this work.

Correspondence to: Dr. Zhen Zhang. Department of Radiation Oncology, Fudan University Shanghai Cancer Center, Fudan University, Shanghai 200032, China. Email: zhen_zhang@fudan.edu.cn.

Background: Radiation enteritis is common in cancer patients with abdominal and pelvic malignant tumors that have received radiotherapy. Regeneration of intestinal stem cells is a critical process for intestine self-repairing post-irradiation. In this study, we attempted to find out the molecules that promote the regeneration of intestinal stem cells to repair the irradiation damage.

Methods: Male C57BL/6 mice were given a single dose of 12 Gy irradiation, and in vitro cultured organoids were given $6 \mathrm{~Gy} \mathrm{X}$-rays to construct the regeneration of intestinal stem cells. Hematoxylin and eosin (H\&E) staining was performed for morphological observation. In situ hybridization was used to detect the expression of Lgr5, and immunofluorescence staining was adopted to detect the expression of CD44. FACS was used to sort CD44 positive cells of crypts. RNA was then extracted, and RNA-Seq was performed. The Wnt11 over-expression cell line was constructed to collect the Wnt11 conditioned medium (CM).

Results: The results showed both Lgr5 and CD44 located at the bottom of normal crypts. The expression of $\operatorname{Lgr} 5$ was lower at day 3.5, 5, but recovered at day 10 post-irradiation compared with the control. However, the expression of CD44 was higher at day 3.5, 5, but recovered at day 10 post-irradiation compared with the control group. The quantitative real-time polymerase chain reaction (qRT-PCR) assay showed consistent results. RNA-Seq results showed that Wnt11 was over-expressed in the irradiation group. After irradiation adding Wnt11 condition medium to culture, the intestinal organoids resulted in a bigger size and more buddings of the newborn organoids compared with the control group.

Conclusions: The expression of CD44 increases during the radiation-induced regeneration of intestinal stem cells while Lgr5 decreases, adding Wnt11 CM can facilitate the proliferation of the newborn organoids after irradiation. Wnt1 1 is a potential target to promote the regeneration of intestinal stem cells to repair the radiation injury.

Keywords: Intestine stem cell; regeneration; CD44; wnt11

Submitted May 18, 2020. Accepted for publication Jul 27, 2020.

doi: $10.21037 /$ atm-20-4542

View this article at: http://dx.doi.org/10.21037/atm-20-4542 


\section{Introduction}

Radiotherapy is one of the most important methods to treat cancer patients. However, patients with abdominal and pelvic malignant tumors who receive radiotherapy may develop radiation enteritis such as diarrhea, abdominal pain, bleeding, intestinal stricture, obstruction, or even perforation, which significantly affects the quality life of the patients (1-3). The treatments for radiation enteritis are mainly enteral and parenteral nutrition support and drug treatment, including mucosal protective agents, anti-inflammatory drugs and intestinal probiotics, or even surgical intervention (1,4-6). Therefore, how to reduce the occurrence of radiation enteritis is a clinical problem in urgent need to be solved.

The intestine epithelium can quickly self-renew every 4-5 days, the fastest tissues among mammalian (7). At normal state, the intestinal stem cells located at the base of the crypt divide daily to produce proliferating cells and maintain homeostasis $(8,9)$. Once the intestine received different kinds of extrinsic or intrinsic injuries, the regeneration response could be triggered to repair the damage (10). Upon intestine injury, R-spondin 3 will help the stem cell recovery by promoting the epithelial regeneration (11). There are cluster cells termed as the revival cell, once intestine damage by irradiation, these cells will undergo transient expansion to promote the regeneration and revive the homeostasis (12).

It was found the irradiation damage could be repaired entirely through the regeneration of intestinal stem cells when the mouse rectum was irradiated lower than 17.5 Gy radiation. Nevertheless, if the irradiation dose exceeded 20 Gy, the intestine damaged significantly, and the intestinal stem cells could not regenerate and repair the irradiation damage (13). The intestinal stem cells can recover the injury caused by irradiation through self-regeneration, which supplies a new way to cure the radiation enteritis. This study aimed to uncover the expression changes of $\operatorname{Lgr} 5$ and CD44 during the regeneration of intestinal stem cells and find out the molecules that may facilitate the regeneration of intestinal stem cells to repair the irradiation damage. We present the following article in accordance with the ARRIVE reporting checklist (available at http://dx.doi. org/10.21037/atm-20-4542).

\section{Methods}

\section{Mice}

Male C57BL/6 aged 8-12 weeks were used. Experiments were performed under a project license (No: 20171416A298) granted by the department of laboratory animal science of Fudan University, in compliance with national guidelines for the care and use of animals. Each study group need at least 3 mice randomisely allocated.

\section{Irradiation}

The mouse was anesthetized with ether and fixed to a plate, then abdomen irradiation (ABI) was given to it using a $5-\mathrm{mm}$ thick lead shield to protect the head and chest. Irradiation was delivered with $250 \mathrm{kVp}$ X-rays produced by X-Rad 320.

\section{Tissue preparation and bistological analysis}

Mice were sacrificed for the cervical dislocation and the small intestinal tissue samples were collected at 3.5, 5, and 10 days after irradiation. These samples were incubated in the $4 \%$ freshly prepared neutral-buffered formaldehyde for 16-18 hours to fix and then embedded in paraffin blocks as previously described $(14,15)$. Four- $\mu$ m sections were used for hematoxylin and eosin (HE)-stained analysis.

\section{Lgr5 in situ bybridization (ISH) analysis}

Freshly prepared 4- $\mu \mathrm{m}$ sections were used for detecting Lgr 5 mRNA. ISH was performed using the QuantiGene ViewRNATM ISH tissue 1-plex assay kit (QVT0200 and QVT0050) according to the manufacturer's instructions. Lgr5 probe (mouse VB1-17159) was bought from Affimetrix.

\section{CD44 immunofuorescence analysis}

Paraffin-embedded tissue sections were used for detecting CD44 by immunofluorescence staining. Subsequently, 4- $\mu \mathrm{m}$ sections were deparaffinized and rehydrated through graded ethanol. Following that, endogenous peroxidase activity was blocked for 10 minutes with PBS holding $0.3 \% \mathrm{H}_{2} \mathrm{O}_{2}$. After that, antibody sections performed antigen retrieval for 20 minutes in $0.1 \mathrm{~mol} / \mathrm{L}$ citrate buffer (PH 6.0). Then, nonspecific antibody binding is blocked for 1 hour by incubation with $10 \%$ normal goat serum. Also, sections were incubated with rat anti-CD44 (BioLegend, 1:200 dilution) overnight at $4{ }^{\circ} \mathrm{C}$ in a humidified chamber. Finally, Rabbitanti-rat secondary antibody was used to incubate the sections.

\section{Small intestine crypt isolation and culture}

The small intestine about $10 \mathrm{~cm}$ from jejunum was isolated 
at day 5 post-irradiation, then opened longitudinally and washed with cold PBS plus penicillin $(100 \mu / \mathrm{mL})+$ streptomycin $(100 \mu \mathrm{g} / \mathrm{mL})$ (called ABS). The tissue was chopped into around $5 \mathrm{~mm}$ pieces and further washed with cold ABS. The tissue fragments were incubated in 5 mM EDTA with PBS for 40 min on ice. After removal of the EDTA medium, the tissue fragments were vigorously suspended by shaking the $50 \mathrm{~mL}$ centrifuge tube. Crypt fractions were at once diluted (1:1) with basic culture medium and centrifuged at $1,200 \mathrm{rpm}$ for $3 \mathrm{~min}$ at 4 degrees. The crypt pellets were resuspended in $10 \mathrm{~mL}$ Basic culture medium. This fraction was passed through 100- and 70- $\mu \mathrm{m}$ cell strainers (BD Bioscience) to remove residual villous material. Isolated crypts were counted and pelleted. A total of 500 crypts were mixed, with $50 \mu \mathrm{L}$ of Matrigel (BD Bioscience) and plated in 24-well plates. After polymerization of Matrigel, $500 \mu \mathrm{L}$ of crypt culture medium Culture medium: advanced DMEM/F12 medium containing penicillin/streptomycin, Glutamax, 10 mM HEPES, 1× $\mathrm{N} 2,1 \times \mathrm{B} 27$ and 1um $\mathrm{N}$-acetylcysteine, growth factors $50 \mathrm{ng} / \mathrm{mL}$ EGF, $500 \mathrm{ng} / \mathrm{mL}$ R-spondin $1,100 \mathrm{ng} / \mathrm{mL}$ noggin.

\section{FACS analysis and RNA-seq}

The small intestine crypts were isolated at day 5 postirradiation. The crypts were incubated in the digestive juice, which pre-warmed and contained $2 \mathrm{~mL}$ TRYPLE express (Gibco Life Technologies), $20 \mu \mathrm{L}$ Y27632 (Sigma-Aldrich), $2 \mathrm{~mL}$ N-acetylcysteine (Sigma-Aldrich), $80 \mu \mathrm{L}$ DNase and $2 \mu \mathrm{L}$ Dispase Type II (Gibco Life Technologies) in $37^{\circ} \mathrm{C}$ for 8 minutes. Quickly, they ended the digestive process by adding DMEM with $10 \%$ fetal bovine serum (Gibco life technology). The mixture was centrifuged at 1,200 rpm for $5 \mathrm{~min}$ at 4 degrees. The cells were passed through $40-\mu \mathrm{m}$ strainers (BD Bioscience) and resuspended with ABS $\left(\sim 1 \times 10^{6}\right.$ cells $\left./ 100 \mu \mathrm{L}\right)$. The cells were counterstained with different fluorescein antibodies, including APC antimouse/human CD44 (Biolegend), PE anti-mouse CD45 (Biolegend), FITC anti-mouseCD326 (Biolegend) and propidium iodide (PI, Sigma-Aldrich), according to the manufacturer's instructions. PI(-) CD45(-) $\operatorname{EpCAM(+)~}$ CD44(+) [marked as CD44(+)] cells are sorted using s flow cytometer (Beckman). The sorted cells were collected, and their RNA was extracted using the RNeasy Plus Mini Kit (Qiagen). The GENEWIZ company did the RNA-seq and analysis work.

\section{Reverse transcriptase (RT)-PCR and quantitative real- time polymerase chain reaction ( $q R T-P C R)$}

Mouse cDNA was synthesized from $500 \mathrm{ng}$ of total RNA using a DNA synthesis kit (Takara). The relative expression of WNT11 was detected by qRTPCR, which was performed using a LightCycler 480 (Roche). The primers used in the qRT-PCR were as follows: 5'-TTCCGATGCTCCTATGAAGG-3' and 5'-GGCTGACAGGTAGCGGGTCT-3' for WNT $11 ; 5$ '-CAGCAACTCCCACTCTTCC-3' and 5'-GGTCCAGGGTTTCTTACTCC-3 ' for GAPDH; 5'-GGGACCAGATGCGATAC-3' and 5 '-AGGAGACTGGCGGGTAG-3' for $\operatorname{Lgr} 5 ; 5^{\prime}-$ GGATTCATCCCAACGCTAT-3' and 5'-ACTCGCCCTTCTTGCTGT-3' for CD44. $2^{-\Delta \Delta C t}$ method was used to calculate the results.

\section{The construction of Wnt11 over-expression cells and collection of Wnt11 conditioned medium (CM)}

CHO cells were used to construct the Wnt11 overexpression cells (CHO-Wnt11 cells). Wnt11 overexpressed plasmid pEZ-Lv185-Wnt11 was purchased from GeneCopoeia, the negative control (NC) and Wnt11expressing lentiviruses were packaged in $293 \mathrm{~T}$ cells according to their instructions. When the $\mathrm{CHO}$ cells were at $80-90 \%$ confluence, they were infected with either NC- or Wnt11-expressing lentiviruses and screened with $50 \mu \mathrm{g} / \mathrm{mL}$ hygromycin. The over-expression of Wnt11 in CHOWnt11 was confirmed by qRT-PCR. CHO-Wnt11 cells are passaged in 1:6 in a T75 flask. The culture medium was collected when the flasks were confluent in about 4 days and replaced with fresh culture medium. Three days later, we collected the culture medium again, then discarded the cells. The first collected medium and the second mixed 1:1 together, then spun down the mix for 5 minutes at 1,500 rpm to remove floating cells and filtered through $0.22 \mu \mathrm{M}$ filter. The Wnt11 CM can be frozen and stored at $-80{ }^{\circ} \mathrm{C}$. The concentration of the Wnt11 CM was $50 \%$ for culturing the organoid.

\section{Quantification and statistical analysis}

The organoids were cultured using Wnt11 CM and control group for 5 days after irradiation. The size of the regenerated alive organoids was measured using ImagePro Plus 6.0 (Media Cybernetics). All data were from three 
A
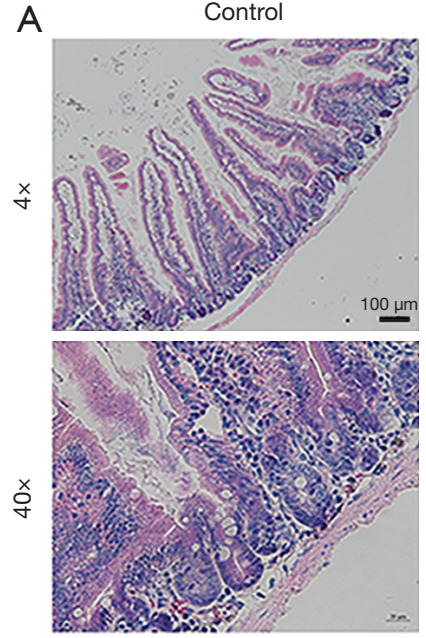

IR12Gy D3.5
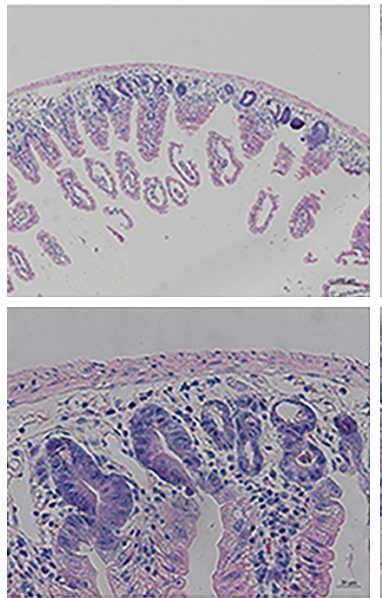

IR12Gy D5
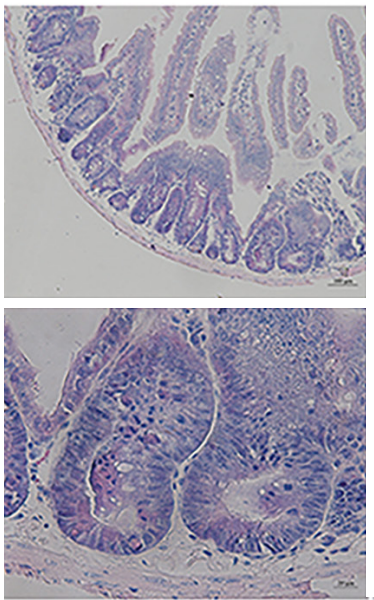

IR12Gy D10

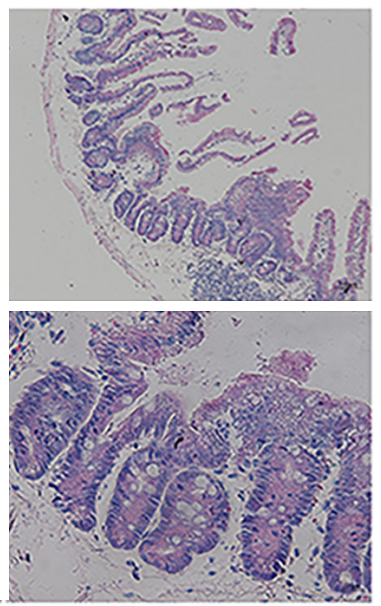

B

Do

D3.5

D5
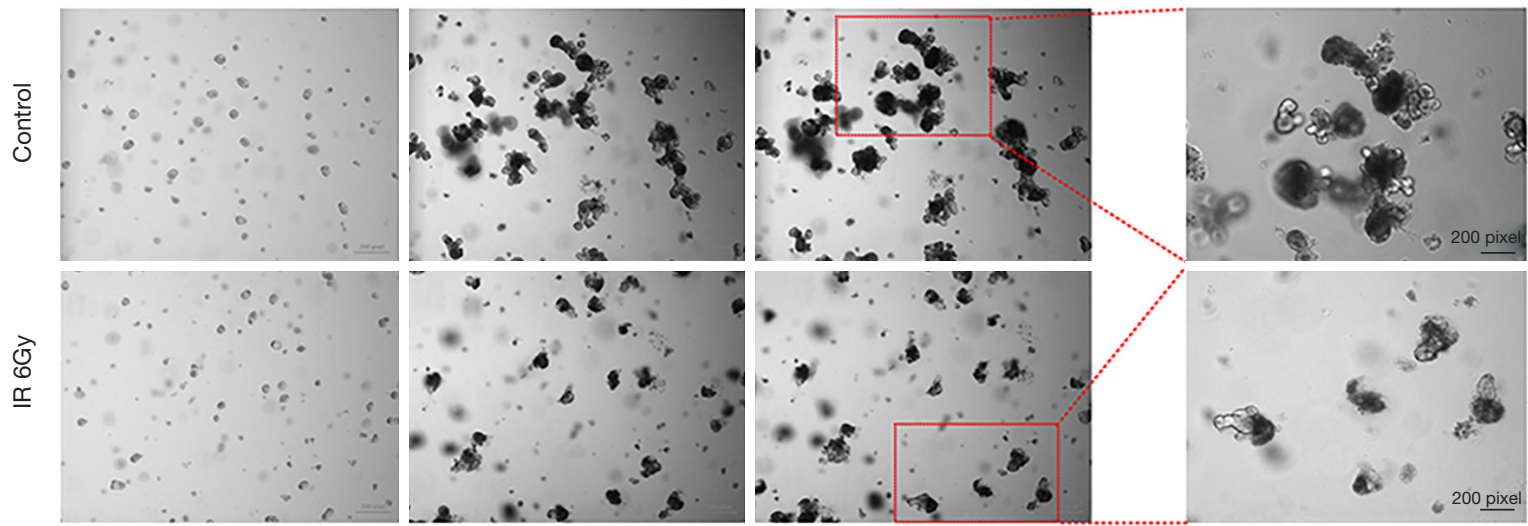

Figure 1 The regeneration of intestinal stem cells in vivo and in vitro. (A) Representative images of the hematoxylin and eosin (H\&E) staining of the small intestine sections from control and irradiated (IR) mice at day 3.5, 5, and 10; (B) representative images of the organoids of the mouse small intestine from control and IR at day 3.5 and 5.

independent experiments and shown as mean \pm standard deviation (SD). One-way ANOVA and Student's $t$-test were performed using GraphPad Prism 6.0 software to determine significant differences between the two groups, with $\mathrm{P}<0.05$ considered significant.

\section{Results}

\section{The regeneration of the intestinal stem cell in vivo and in vitro}

According to the literature report $(14,15)$, we chose the dose of 12 Gy to establish the regeneration model of the mouse small intestine. As shown in Figure 1A, compared with the normal control group (unirradiated), there were only a few regenerated crypts in the intestinal circle on the 3.5th day in the ABI group. However, the volume and number of regenerated crypts increased significantly on the 5 th day. On the 10th day, the crypts began to recover as the crypts gradually became more and smaller, and the size and number of crypts were like those in the normal control group. Under high magnification, the volume of the normal control crypts was smaller and regularly arranged, while the size and shape of the newborn one on the 3.5 th day and fifth-day post-irradiation were larger and irregular, and the size and shape of the newborn one on the 10th day gradually tended to be normal.

We chose the dose of 6 Gy irradiation to set up the regeneration model of small intestinal organoid in vitro. 
A
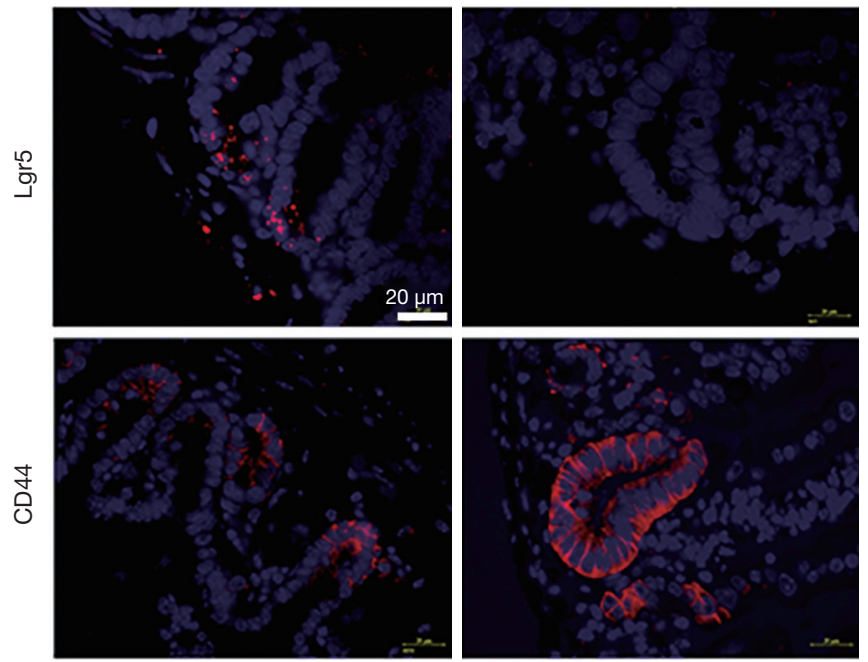

B

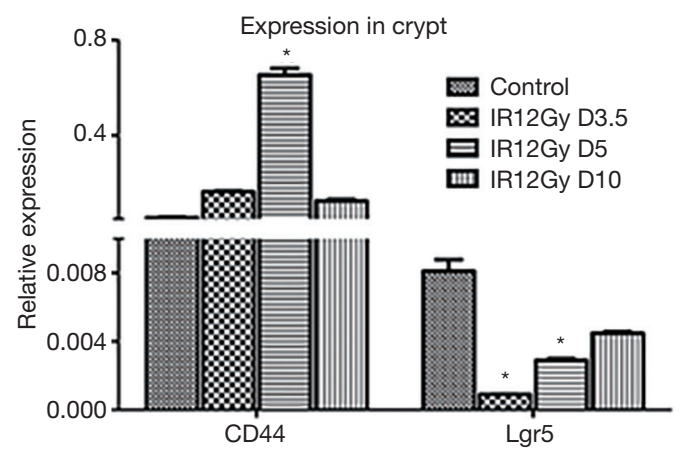

IR12Gy D3.5
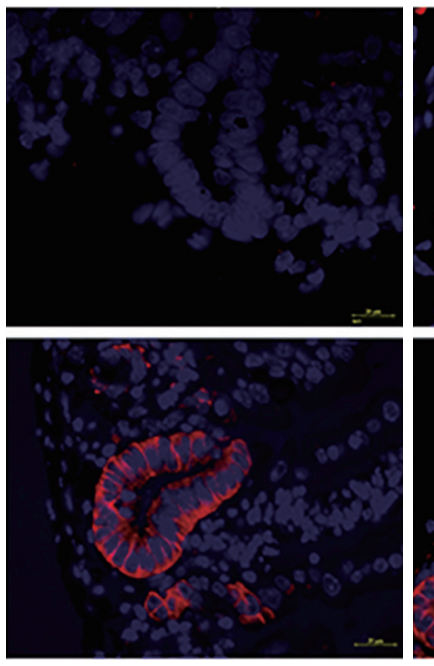

IR12Gy D5
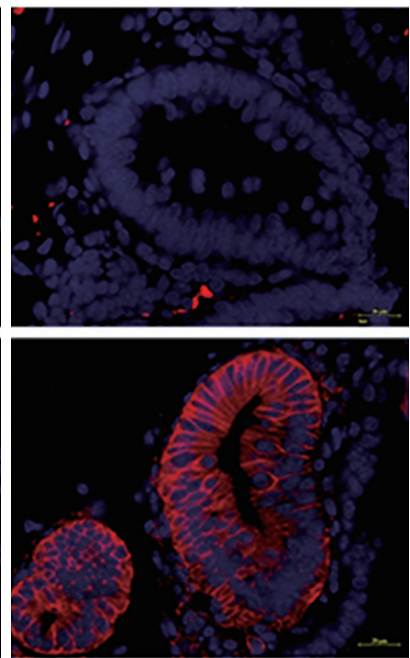

IR12Gy D10
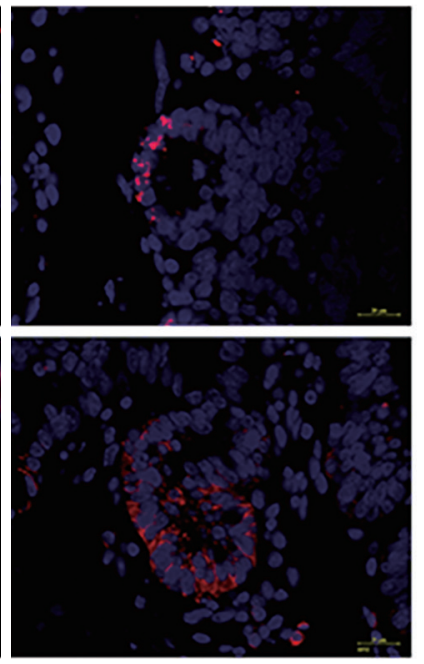

C

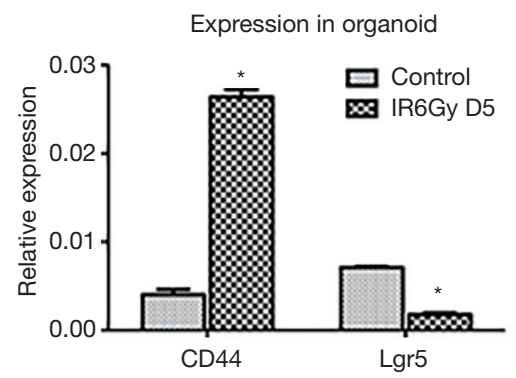

Figure 2 The expression of CD44 is higher in the regenerated crypts while Lgr5 is lower. (A) Representative images (40x) of Lgr5 in situ hybridization staining and CD44 immunofluorescence staining of intestinal sections in control and IR mice at day 3.5, 5 and 10. (B) The expressions of Lgr5 and CD44 of mouse small intestine crypts were measured by quantitative real-time polymerase chain reaction (qRT-PCR) in control and IR mice at day 3.5, 5 and 10. (C) The expressions of Lgr5 and CD44 of mouse small intestinal organoids were measured by qRT-PCR in control and IR at day 5. The data shown are the means \pm SDs from at least three independent experiments. *, $\mathrm{P}<0.05$.

The small intestinal organoids were cultured after carefully isolated. After 0 and 6 Gy irradiation, microscopic observation showed that on the 1st and 2nd day after 6 Gy irradiation, the organoids did not grow, and the initial crypt cells gradually broke down and died (data not shown). While on the 3.5 th day, the surviving crypt stem cells proliferated gradually, and organoids with small intestinal cavities could be identified. Organoids sprouted and grew slowly on the 5th day. However, the unirradiated organoids sprouted and grew on the 3.5 days. Budding increased in bulk on the 5th day, and many apoptotic cells fulfilled the intestinal cavity of the organoid showing black (Figure 1B).

\section{The expression of CD44 is higher in the regenerated crypts, while Lgr5 is lower}

We used ISH to detect the expression changes of Lgr5 that considered a biomarker for intestine stem cells in the intestinal crypts of mice. The results showed that in the normal unirradiated control group, the expression of Lgr5 was concentrated on the bottom of the crypts. However, on the 3.5 th and fifth days after irradiation, the expression of Lgr 5 was not detected in the crypts. While on the 10th day, the expression of Lgr5 was detected again at the bottom of the crypts (Figure 2A). It is shown that the expression of $\operatorname{Lgr} 5$ is lower during the regenerating process of intestinal 
A

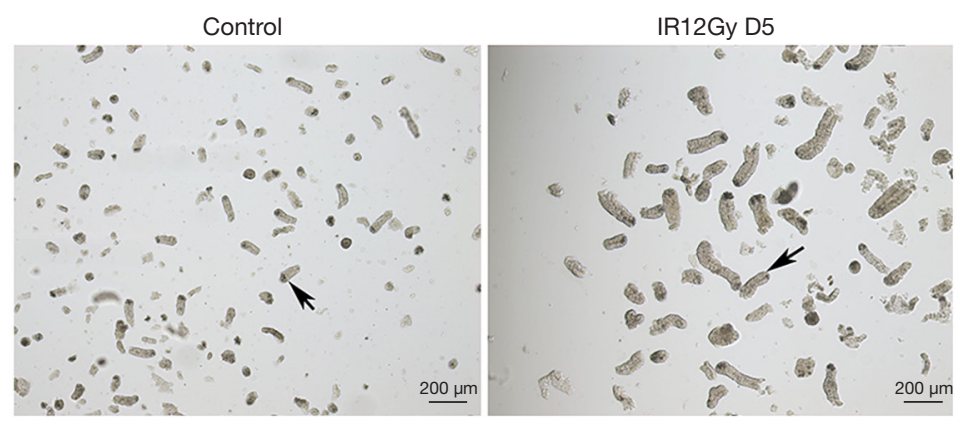

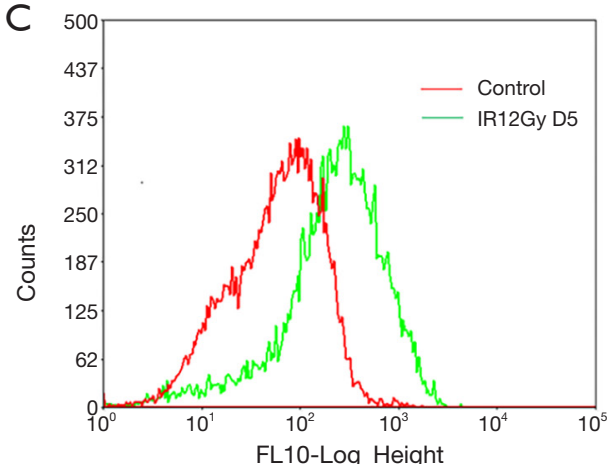

B
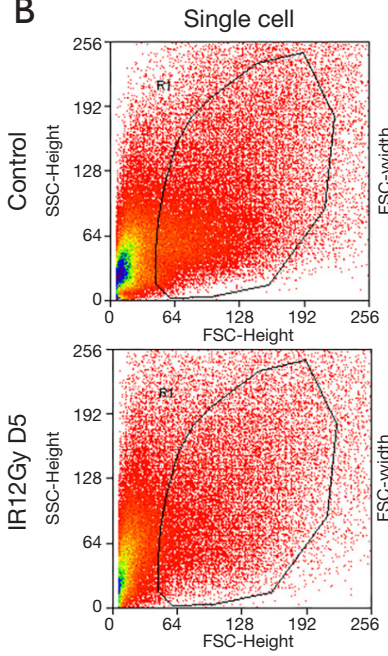
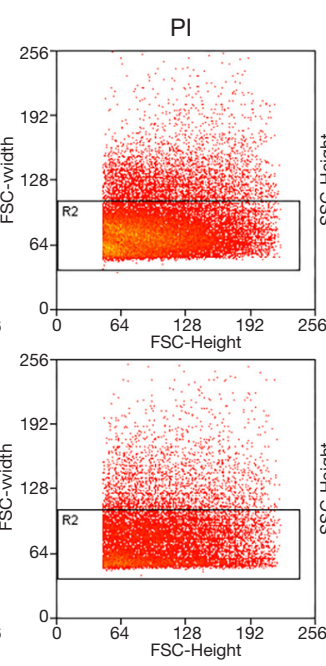
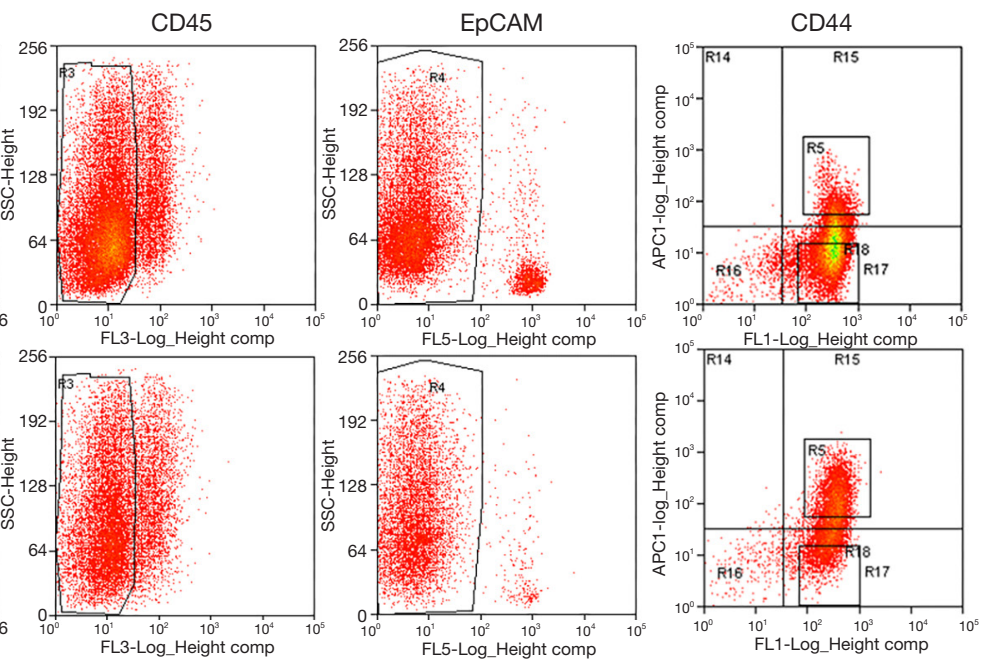

Figure 3 FACS analysis of CD44(+) cells. (A) Representative images of mouse crypts in control and irradiated at day 5 , black arrows pointing to the crypts. (B) Representative image of the dot plot analysis of FACS, propidium iodide (PI) staining for live cells, CD45 staining for white cells, EpCAM staining for epithelial cells. (C) The peak map analysis of CD44(+) in control and IR group.

stem cells.

Tissue immunofluorescence assay was used to detect the expression of CD44 during the process of intestine stem cell regeneration of mice after radiation injury. The results showed that in the control group, the expression of CD44 was confined at the bottom of the small intestinal crypt. However, on the 3.5 th and fifth days after irradiation, all the regenerated crypts expressed CD44. However, on the 10th day, the expression of CD44 has confined to the bottom of the crypts again (Figure 2B). It is suggested that CD44 is significantly increased in the regenerating process of mouse intestinal stem cells, showing that CD44 may be involved in the regulation of intestinal stem cell regeneration.

qRT-PCR was used to detect the expression of $\operatorname{Lgr} 5$ and CD44 to further explore the changes of Lgr5 and CD44 during the process of regeneration. The expression of $\operatorname{Lgr} 5$ was high in the control group but lower in the 3.5 th and fifth-day post-irradiation. Meanwhile, they recovered a little on day 10 in the crypts. However, the expression of CD44 was higher on day five compared with other groups. We also detected the expression of Lgr5 and CD44 in the organoid. Consistent with crypts, the expression of Lgr5 was lower, while the expression of CD44 was higher in the regeneration organoid.

\section{FACS analysis of CD44(+) cells}

To further find out the role of CD44 in the regenerating of intestinal stem cells. We isolated crypts, both the unirradiated control group and the ABI group (Figure $3 A$ ). The isolated crypts are digested into single cells to be sorted for CD44(+) cells. PI staining was used to select the live cells. CD45 staining was used to exclude the white cells. EpCAM staining is used for selecting the epithelial cells. 

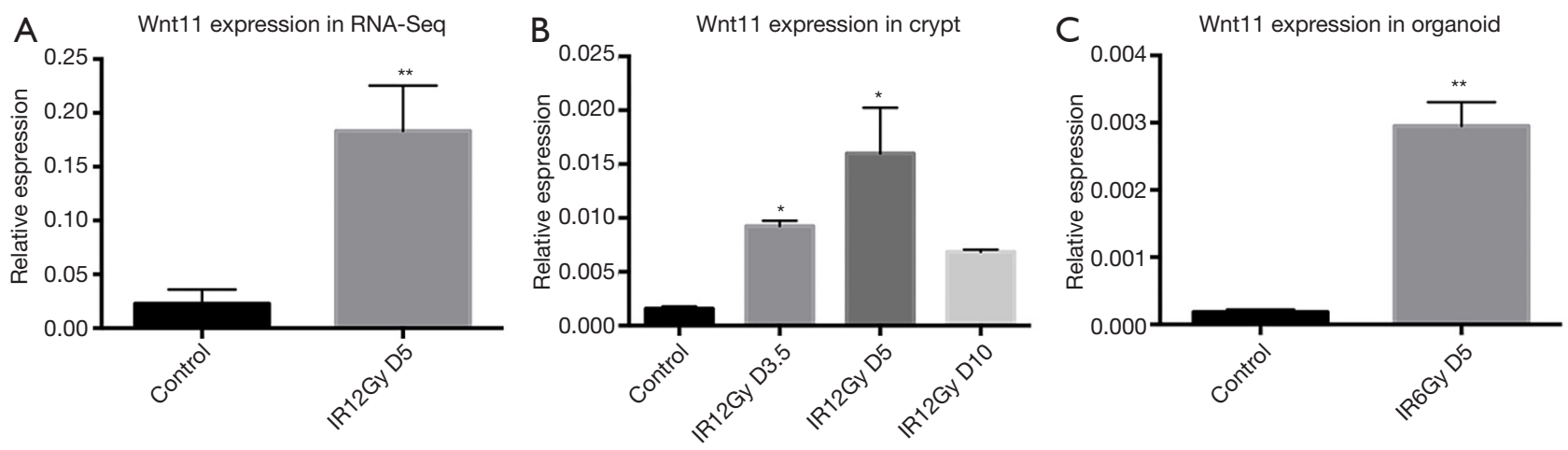

Figure 4 Wnt11 increases significantly in the regenerating intestinal stem cells. (A) The expression of Wnt11 in the control and irradiated group according to the RNA-seq results. (B) The expression of Wnt11 of mouse small intestine crypts was measured by quantitative realtime polymerase chain reaction (qRT-PCR) from control and irradiated (IR) mice at day 3.5, 5, and 10. (C) The expression of Wnt11 of mouse small intestine organoids was measured by qRT-PCR from control and IR at day 5 . The data shown are the means \pm SDs. *, $\mathrm{P}<0.05$; **, $\mathrm{P}<0.01$.

The sorting results showed that the ration of CD44(+) cells was much higher in the ABI group than the control group (Figure 3B). The peak of CD44(+) cells in the irradiation group shifted to the right (Figure 3C) by peak map analysis. These results showed that the expression of CD44 increased significantly in the regeneration crypts.

\section{Wnt11 increased significantly in the regenerating intestinal stem cells}

We performed RNA-seq to compare the difference between CD44(+) cells and the unirradiated control group. We analyzed the results of the RNA-seq and found that the expression of Wnt11 was much higher in the irradiation group than the control group (Figure 4A). Then we detected the expression of Wnt11, both crypts, and organoids. The results have shown that Wnt11 increased significantly in the regenerating intestinal stem cells both in the crypts and organoids (Figure 4B,C).

\section{Wnt11 can facilitate the regeneration of the intestinal stem cell}

We constructed the CHO-Wnt11 cell line to collect the Wnt11 CM. Wnt11 was expressed in the CHO-Wnt11 cells more than in CHO-NC cells by qRT-PCR (Figure $5 A$ ). To further confirm whether Wnt11 can help the regeneration of the intestinal stem cell, the culture medium of intestinal organoid was replaced quickly with Wnt11 CM and control respectively after irradiation. The size was bigger in the
Wnt11 CM group than the control group 5 days later (Figure 5B). Image-Pro Plus 6.0 was used to measure the size of the regenerated alive organoids. The results showed that the pixel of the Wnt11 CM group is larger than the control group, with an average of $18,625 \pm 798.5$ pixels for the Wnt11 CM group, while $10,105 \pm 417.7$ pixels for the control group (Figure 5C). The budding number also was calculated. The average budding number of the Wnt11 CM group is $7.151 \pm 0.288$, but the control group is $4.404 \pm 0.2526$ (Figure 5D), indicating that Wnt11 CM can facilitate the regeneration of the intestinal stem cell.

\section{Discussion}

In this study, we observed the regeneration of mouse intestinal stem cells both in vivo and in vitro. We found Lgr5 was expressed less, but CD44 was expressed higher in the regenerating intestinal stem cells. Then we selected the CD44(+) cells of the regenerating crypts to go through RNA-seq. We found the expression of Wnt11 was significantly higher in the irradiation group and conformed by qRT-PCR both in the regenerating crypts and organoids. Furthermore, we showed that Wnt11 CM could help the organoids to proliferate post-irradiation. The above results show that Wnt11 can facilitate the regeneration of intestinal stem cells after irradiation.

$\operatorname{Lgr} 5$ is considered a biomarker for intestinal stem cells. It was reported that single Lgr5 + cells could grow into a "minigut" structure that comprised all kinds of differentiated intestinal cell types in vitro once given the 
A

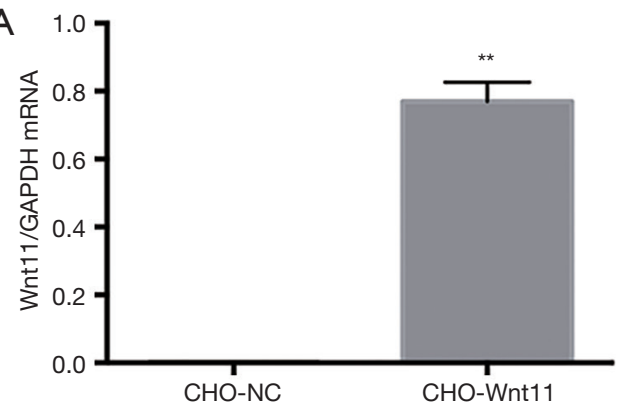

C

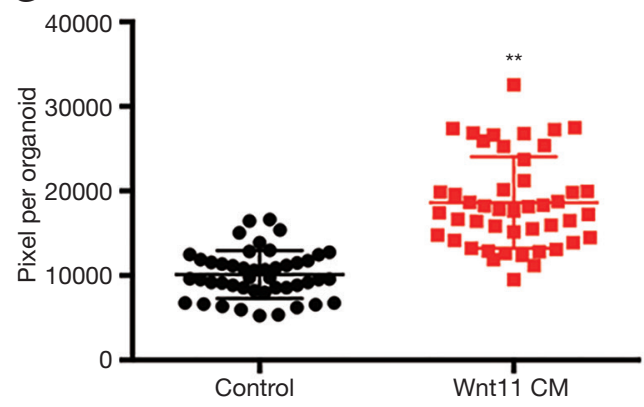

B

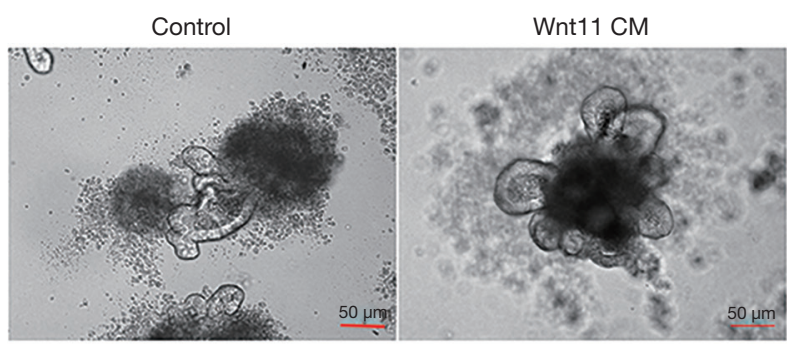

D

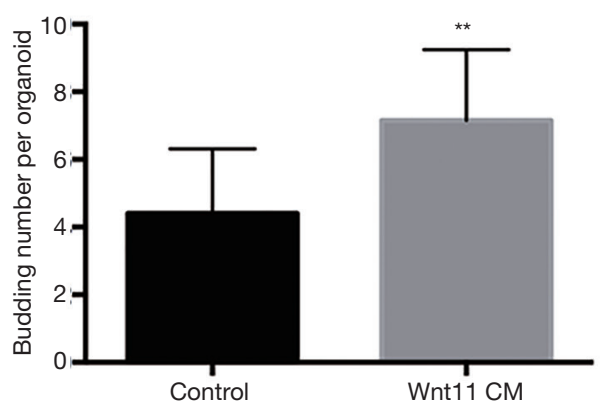

Figure 5 Wnt11 can facilitate the regeneration of the intestinal stem cell. (A) The expression of Wnt11 in CHO-Wnt11 cell lines and CHO-NC cell lines by quantitative real-time polymerase chain reaction (qRT-PCR). (B) Representative images of newborn organoids of the mouse small intestine culturing by Wnt11 conditioned medium (CM) and the control after IR at day 5. (C) The sizes of the newborn organoids of the Wnt11 CM and control group were measured by calculating the pixels of the organoids. (D) The budding of the newborn organoids of the Wnt11 CM and control group. The data shown are means \pm SDs. ${ }^{* *}, \mathrm{P}<0.01$.

proper condition medium (16). Another report has shown that $\operatorname{Lgr} 5+$ cells played a significant role in radiationinduced regeneration; the regeneration response was dramatically altered after depletion of Lgr5+ intestinal cells (17). However, in Hua's (14) research, they found that after the Lgr5-lac Z transgenic mice treated with $12 \mathrm{~Gy}$, the Lgr5-Laz intestinal cells were nearly not detected on day 2 and day 3 post-irradiation, but less was found on day 5 postirradiation, while recovered on day 10 post-irradiation. Our founding was the same as their results (Figure 2B), showing a complicate role of $\operatorname{Lgr} 5$ in regulating the regeneration of intestinal stem cells.

CD44 is a transmembrane glycoprotein that plays a type of function (18). The CD44+ cells in the mouse intestine are mainly in the stem cell region at the bottom of the crypt (19). CD44+ cells isolated from mice, small intestine, and colon are recognized as intestine stem cells because these cells express high levels of stem cell-associated genes (20), while little is known about whether CD44+ cells contribute to the regeneration of intestinal stem cells. Our study has shown that during the radiation-induced regeneration of intestinal stem cells, the expression of CD44 increased significantly, showing that there will be a correlation between CD44 and regeneration. Therefore, we perform RNA-seq using the sorting the CD44(+) cells and the unirradiated control cells. We try to find out some genes or signal pathways that change during the regenerating process, which may play a role in regulating intestinal stem cell regeneration.

By analysis of the RNA-seq data, we found Wnt11 was highly expressed in the CD44(+) cell group. Wnt11 is one of the Wnt-family members and regulates cellular behavior by non-canonical mechanisms (21). Wnt11 is also playing a role in mammalian heart development (22). During the growth process of the nephron progenitor, Wnt11 regulates the organization of cells by non-canonical mechanism (23). As mentioned above, Wnt11 plays a role in regulating the development of progenitors. In our study, we also found that the expression of Wnt11 was more in the regenerating stem cells. By adding Wnt11 CM to culture the organoids after irradiation, the newborn organoids proliferated much better than the control group. Our study found that both CD44 and WNT11 expressed higher during the 
regeneration of the intestinal stem cells, but there was a study reported that WNT11 overexpressing SKOV-3 cells showed lower expression of CD44 (24), which was not consistent with our results, indicating that the interaction between CD44 and WNT11 need to be fully explored. It was reported that Wnt1 combines with another noncanonical Wnt ligand Wnt5a can jointly inhibit the activity of classical Wnt/ $\beta$-catenin $(25,26)$. Wnt5a can promote intestine regeneration through the TGF- $\beta$ signal pathway (27). We hypothesis that Wnt11 may promote the regeneration of intestinal stem cells through a non-conical Wnt signal pathway by interacting with CD44, which needs further research to prove.

As our study presented, on the 10th day after irradiation, intestinal stem cells repaired the radiation damage through self-regeneration, and the shape and size of the crypt began to return to normal. At this time, the expression of CD44 and Wnt11 dropped to a normal level. However, the expression of $\operatorname{Lgr} 5$ resumed at the crypt bottom, indicating that the conical Wnt signal pathway was activated again. Also, it played a role in supporting the homeostasis of the intestinal crypt. However, these speculations need to be confirmed by further research.

\section{Conclusions}

In summary, our results confirm the expression of CD44 increases during the radiation-induced regeneration of intestinal stem cells while that of $\operatorname{Lgr} 5$ decreases, adding Wnt11 CM can facilitate the proliferation of the newborn organoids after irradiation. Our findings indicate we can focus on the CD44 related signal pathway to study the regeneration of intestinal stem cells, and Wnt11 is a potential target to facilitate the regeneration of intestinal stem cells to recover from the radiation-induced damage, which may be a hopeful method to treat radiation enteritis.

\section{Acknowledgments}

Funding: This work was supported by the National Natural Science Foundation of China (31470826, 31670858 , 81773357). Shanghai ACA Foundation (SACACY19B04), Fudan University Shanghai Cancer Center Foundation (YJQN201921).

\section{Footnote}

Reporting Checklist: The authors have completed the
ARRIVE reporting checklist. Available at http://dx.doi. org/10.21037/atm-20-4542

Data Sharing Statement: Available at http://dx.doi. org/10.21037/atm-20-4542

Conflicts of Interest: All authors have completed the ICMJE uniform disclosure form (available at http://dx.doi. org/10.21037/atm-20-4542). The authors have no conflicts of interest to declare.

Ethical Statement: The authors are accountable for all aspects of the work in ensuring that questions related to the accuracy or integrity of any part of the work are appropriately investigated and resolved. Experiments were performed under a project license (No.: 20171416A298) granted by the department of laboratory animal science of Fudan University, in compliance with national guidelines for the care and use of animals.

Open Access Statement: This is an Open Access article distributed in accordance with the Creative Commons Attribution-NonCommercial-NoDerivs 4.0 International License (CC BY-NC-ND 4.0), which permits the noncommercial replication and distribution of the article with the strict proviso that no changes or edits are made and the original work is properly cited (including links to both the formal publication through the relevant DOI and the license). See: https://creativecommons.org/licenses/by-nc-nd/4.0/.

\section{References}

1. Rehailia-Blanchard A, He MY, Rancoule C, et al. Physiopathology and pharmacological perspectives in the treatment of radiation enteritis. Cancer Radiother 2019;23:240-7.

2. Wang $\mathrm{Y}$, Kong $\mathrm{W}, \mathrm{Lv} \mathrm{N}$, et al. Incidence of radiation enteritis in cervical cancer patients treated with definitive radiotherapy versus adjuvant radiotherapy. J Cancer Res Ther 2018;14:S120-4.

3. Rai M, Hookey L, Bechara R. A case of radiationinduced enteritis diagnosed by video capsule endoscopy. Gastrointest Endosc 2019;90:315-6.

4. He JY, Wang WZ, Qi HZ, et al. Use of recombinant Lactobacillus sakei for the prevention and treatment of radiation-induced enteritis. Med Hypotheses 2018;119:37-40.

5. Farhood B, Hassanzadeh G, Amini P, et al. Mitigation 


\section{Page 10 of 10}

of radiation induced gastrointestinal system injury using resveratrol or alpha-lipoic acid: A pilot histopathological study. Antiinflamm Antiallergy Agents Med Chem 2020;19:413-24.

6. Jang H, Lee J, Park S, et al. Baicalein Mitigates RadiationInduced Enteritis by Improving Endothelial Dysfunction. Front Pharmacol 2019;10:892.

7. Beumer J, Clevers H. Regulation and plasticity of intestinal stem cells during homeostasis and regeneration. Development 2016;143:3639-49.

8. Yousefi M, Li L, Lengner CJ. Hierarchy and Plasticity in the Intestinal Stem Cell Compartment. Trends Cell Biol 2017;27:753-64.

9. Buczacki S. Fate plasticity in the intestine: The devil is in the detail. World J Gastroenterol 2019;25:3116-22.

10. Qi D, Shi W, Black AR, et al. Repair and regeneration of small intestine: A review of current engineering approaches. Biomaterials 2020;240:119832.

11. Harnack C, Berger H, Antanaviciute A, et al. R-spondin 3 promotes stem cell recovery and epithelial regeneration in the colon. Nat Commun 2019;10:4368.

12. Ayyaz A, Kumar S, Sangiorgi B, et al. Single-cell transcriptomes of the regenerating intestine reveal a revival stem cell. Nature 2019;569:121-5.

13. Semont A, Demarquay C, Bessout R, et al. Mesenchymal stem cell therapy stimulates endogenous host progenitor cells to improve colonic epithelial regeneration. PLoS One 2013;8:e70170.

14. Hua G, Thin TH, Feldman R, et al. Crypt base columnar stem cells in small intestines of mice are radioresistant. Gastroenterology 2012;143:1266-76.

15. Hua G, Wang C, Pan Y, et al. Distinct Levels of Radioresistance in Lgr5(+) Colonic Epithelial Stem Cells versus Lgr5(+) Small Intestinal Stem Cells. Cancer Res 2017;77:2124-33.

16. Sato T, Vries RG, Snippert HJ, et al. Single Lgr5 stem cells build crypt-villus structures in vitro without a mesenchymal niche. Nature 2009;459:262-5.

17. Metcalfe C, Kljavin NM, Ybarra R, et al. Lgr5+ stem

Cite this article as: Liang L, Shen L, Fu G, Yao Y, Li G, Deng Y, Zhang H, Zhou M, Yang W, Hua G, Zhang Z. Regulation of the regeneration of intestinal stem cells after irradiation. Ann Transl Med 2020;8(17):1063. doi: 10.21037/ atm-20-4542

\section{Li et al. Wnt11 facilitates the regeneration of intestinal stem cells}

cells are indispensable for radiation-induced intestinal regeneration. Cell Stem Cell 2014;14:149-59.

18. Morath I, Hartmann TN, Orian-Rousseau V. CD44: More than a mere stem cell marker. Int J Biochem Cell Biol 2016;81:166-73.

19. Wielenga VJ, Smits R, Korinek V, et al. Expression of CD44 in Apc and Tcf mutant mice implies regulation by the WNT pathway. Am J Pathol 1999;154:515-23.

20. Wang F, Scoville D, He XC, et al. Isolation and characterization of intestinal stem cells based on surface marker combinations and colony-formation assay. Gastroenterology 2013;145:383-95.e1-21.

21. Nagy, II, Railo A, Rapila R, et al. Wnt-11 signalling controls ventricular myocardium development by patterning $\mathrm{N}$-cadherin and beta-catenin expression. Cardiovasc Res 2010;85:100-9.

22. Zhou W, Lin L, Majumdar A, et al. Modulation of morphogenesis by noncanonical Wnt signaling requires ATF/CREB family-mediated transcriptional activation of TGFbeta2. Nat Genet 2007;39:1225-34.

23. O'Brien LL, Combes AN, Short KM, et al. Wnt11 directs nephron progenitor polarity and motile behavior ultimately determining nephron endowment. Elife 2018;7:e40392.

24. Vajihe Azimian-Zavareh, Ghamartaj Hossein, Marzieh Ebrahimi, et al. Wnt11 alters integrin and cadherin expression by ovarian cancer spheroids and inhibits tumorigenesis and metastasis. Exp Cell Res 2018;369:90-104.

25. Cohen ED, Miller MF, Wang Z, et al. Wnt5a and Wnt11 are essential for second heart field progenitor development. Development 2012;139:1931-40.

26. Bisson JA, Mills B, Paul Helt JC, et al. Wnt5a and Wnt11 inhibit the canonical Wnt pathway and promote cardiac progenitor development via the Caspase-dependent degradation of AKT. Dev Biol 2015;398:80-96.

27. Miyoshi H, Ajima R, Luo CT, et al. Wnt5a potentiates TGF-beta signaling to promote colonic crypt regeneration after tissue injury. Science 2012;338:108-13. 